\title{
Assessment of Antepartum Depression and its Effect on Pregnancy Outcome in Two Primary Health Care Units in Qaliobia Governorate, Egypt
}

\author{
Ola Abdelmoniem Mostafa ${ }^{1 *}$, Mervat El-Rafie ${ }^{1}$, Eman T. Al Sayed ${ }^{1}$, Mohamed A. Khalil $^{2}$ D, Sherry M. Zaki ${ }^{1}$ \\ ${ }^{1}$ Department of Public Health and Community Medicine, Faculty of Medicine, Cairo University, Cairo, Egypt; ${ }^{2}$ General Psychiatry \\ Unit and addiction treatment Unit, Faculty of Medicine, Cairo University, Cairo, Egypt
}

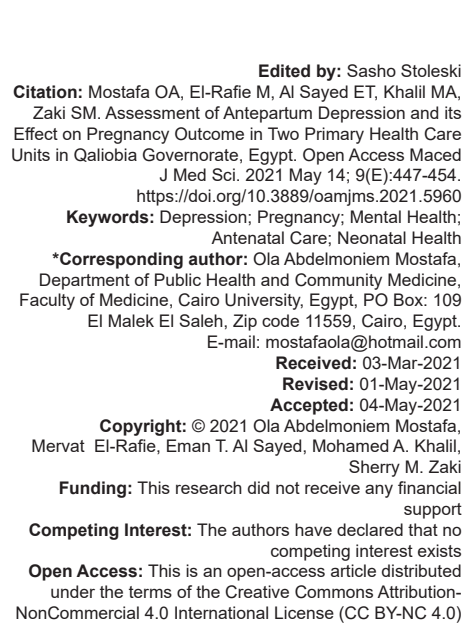

Introduction

Antepartum depression is a major public health problem affecting pregnant women all over the world, imposing negative effects on mothers and birth outcome [1].

With the slogan "no health without mental health," The World Health Organization placed mental illness at the top of its agenda about a decade ago [2].

Antepartum depression affects $10 \%$ of pregnant women worldwide, reaching up to $15.6 \%$ more in developing countries [3]. Pregnant women living in low- and middle-income countries are at high risk of antepartum depression [4].

In developing countries, including Egypt, depression is currently considered to be a major public health issue and is expected to become the most common cause of disability. It is considered a barrier to maternal health improvement [5].
Depression is the most common pregnancy psychiatric disorder and is linked to psychosocial and obstetric factors [6].

Untreated psychiatric disorders may interrupt social life and can have adverse effects on fetal and neonatal growth, so recognizing women at risk of developing psychiatric disorders during pregnancy and implementing timely management is essential [7].

Previous studies from middle-income countries and community-based research were conducted to examine the relationship of antenatal depression with adverse birth outcomes. Low birth weight (LBW) and preterm delivery were significantly associated with antepartum depression [8].

Although mental health promotion is a priority to reach the Sustainable Development Goals [9], antepartum depression is still not well known. It is a neglected component of the health care system in many low- and middle-income countries, including Egypt [8].

Health care staff delivering antenatal care (ANC) services are not qualified to provide mental health 
services in the regular ANC visits, and therefore the diagnosis of antepartum depression is often missed [10].

This study aims at assessing the prevalence of antepartum depression among rural Egyptian pregnant women living in Shebien el Kanater, Qaliobia, Egypt. Moreover, to identify its effect on birth outcome such as LBW, prematurity, neonatal intensive care unit (NICU) admission, and death in $1^{\text {st }}$ month of life.

\section{Methods}

\section{Study design and setting}

Study design

A prospective cohort design.

\section{Study setting}

The proposed study was carried out in Shebien el Kanater, a rural district located in Qaliobia Governorate, in the Nile Delta, North to Cairo (50 km). Qaliobia governorate is composed of seven major villages and 37 satellites. It is occupied by 473,276 inhabitants, mostly working in agriculture [11].

\section{Study site}

Two primary health care (PHC) units (out of all eight). (Nawa PHC and Alkashesh PHC).

\section{Study participants}

\section{Eligibility criteria}

Inclusion criteria

Any pregnant women in the third trimester, aged between 15 and 49 years, and attending a PHC unit in Shebein el Kanater, Qaliobia Governorate to receive her regular ANC services.

\section{Exclusion criteria}

Pregnant women with any medical complications during pregnancy, or is suffering from preexisting psychiatric disorder (as mentioned by the participant or reported in her record), and those who refused to participate in the study.

\section{Sample size and type}

Based on the study performed by Apter et al., 2013, the prevalence of antepartum depression was $20 \%$ (precision $\pm 5 \%$ ), and the target population susceptible to suffer antepartum depression in the study area was about 1500 pregnant women in the reproductive age (15-49 years). Using OpenEpi sample size calculator [12], the required sample size was estimated to be 212 women within the same age group, with power of $95 \%$ and design effect of 1.0 . An additional $10 \%$ was added to compensate for the non-response and dropouts; hence, the total sample size was calculated to be 232 pregnant women in the reproductive age (15-49 years).

\section{Sample type}

A multistage random technique was employed for selecting pregnant women. In the first stage, $2 \mathrm{PHC}$ units (out of all 8) were selected by cluster random sample; the number of women recruited from each unit was determined in relation to number of registered women within the age group. Within each unit, women were selected using a simple random sample. The selected women were interviewed and this interview lasted for 25-30 min.

\section{Procedures and data collection}

Preparatory phase

Pilot study

The data collection tools were tested on 30 pregnant women to assess comprehension, practicability, and reliability of the questionnaires. The required modifications were added to the study tools, which were mainly the simplification of Hamilton questions. They were not included in the study sample.

\section{Data collection phase}

- Eligible women (examined by obstetrician, healthy, and free from complications) were invited for an interview using a structured questionnaire form. The interview took place at the ANC room within the unit. Collection of data was performed twice weekly, interviewing 10 pregnant women per day. The data collection form gathered the following data using closedended question format:

1. Sociodemographic and economic status of the interviewees using previously validated socioeconomic status (SES) scale and most commonly used in health research, proposed by Fahmy and El-Sherbini. It was originally published in 1983 [13] and updated in 2015 [14]. This scale covers seven domains with a total score of 48 points, namely 1 wife/husband education, 2 - wife/husband employment, 3 - family number, 4 - crowding index, 5 - home sanitation, 6 - economic level, 
and 7 - computer use. The total score of SES was calculated and the cutoff points to be used for SES classification, where a high level was indicated as at least $70 \%$ (33.6-48), a medium level as $40-<70 \%(19.2->33.6)$, and a low level as <40\% (>19.2).

2. Obstetric history: To gather information about previous pregnancies, abortion, number of children, and mode of delivery.

3. The Hamilton Rating Scale for Depression (HRSD) [15]: Which is considered the gold standard among existing instruments for assessing depressive symptoms [16].

HRSD is the most frequently used measure of depression severity in clinical trials [17] and depression studies [18]. In addition to that, it has been used as a reference for the development of new scales for assessing depression severity [19]. Furthermore, it has been a favored scale in the evaluation of depression treatment [15].

The scale comprises altogether 17 items; items are scored on a continuum of $0-4$, so the higher the score, the more severe the depression.

The cutoff points for the score were as follows:

- $\quad$ 0-7: Normal,

- 8-13: Mild depression,

- 14-18: Moderate depression,

- 19-22: Severe depression.

- $\quad \geq 23$ : Severe depression [20].

4. Neonatal information

The baby was examined twice in the PHC unit with the help of a well-trained nurse.

- $\quad$ The first examination was performed within 1 week after delivery, where the neonate was brought by a relative for:

- Measurement of weight, length, and head circumference. These measurements were taken and recorded according to the $\mathrm{WHO}$ instruction [21].

- $\quad$ Collecting data about time of delivery; fullterm or pre-term, and breastfeeding.

- $\quad$ The second follow-up contact was 1 month later for collection of the following data:

Neonatal morbidities, NICU admission and its reasons, and neonatal mortalities in $1^{\text {st }}$ month.

- Unfavorable birth outcome was assessed including preterm and LBW.

There were no dropouts due to the researchers' continuous contact with the mothers. Furthermore, nurses encouraged mothers to participate in the study, and sometimes they made home visits to reach them.

\section{Data management and analysis}

Data entry was carried out using Statistical Package for the Social Science (SPSS) version 21.0 (IBM,
SPSS, USA). Variables were examined for normality. Data were presented in simple, cross-tabulation, and graphs. Categorical variables were expressed as proportions and percentage; Chi-square and Fisher's exact tests were applied. ANOVA test was used to compare depression among groups such as age groups. Continuous variables were expressed using mean \pm standard deviation, median, and interquartile range; tests of significance were used appropriately for comparison.

Different adverse birth outcomes were tested versus different confounding variables. Birth outcome was dichotomized into favorable (0) and unfavorable (1). Unfavorable birth outcome included LBW, premature, NICU admission, and neonatal mortality in $1^{\text {st }}$ month. Significant predictors at the bivariate level were used for the generation of multivariate logistic regression model. $P<0.05$ was considered statistically significant.

\section{Possible risk to participants}

None.

\section{Ethical considerations}

- $\quad$ Ethical review committee approval of the study was obtained from the review board of Public Health Department, Faculty of Medicine, Cairo University. Informed consent was obtained from all participants before their enrolment in the study.

- Data confidentiality and informants' identity privacy were maintained throughout the study. Filled questionnaires were coded and accessed by the researchers only.

\section{Results}

The mean age of participant mothers was $25.9 \pm$ 4.8 years ( $\mathrm{min}$ is 18 and $\max$ is 40 ) and the mean age at marriage was $19.1 \pm 2.6$ years ( $\min$ is 14 and max is 32 ).

About one-fifth of the participants were illiterate or could only read and write and about one-fifth had a college education or higher. About one-tenth of their husbands were illiterate or could only read and write and almost one-fifth had a college education or higher. The majority of participant mothers were unemployed, while four-fifths of their husbands were employed. More than threequarters of participants reported that their family income was just enough. Little more than two-thirds of participants had a family size of $<5$ members and the majority have a crowding index of 2 or more. More than two-fifths of participants reported that they had never used a computer, as shown in Table 1. The vast majority of women reported having refuse disposal but no sewage disposal. 
Table 1: Demographic and socioeconomic characteristics of the study participants

\begin{tabular}{|c|c|c|}
\hline Characteristics & Number (300) & Percentage \\
\hline Age in years (Mean $\pm S D)$ & $25.9 \pm 4.8$ & \\
\hline Age at marriage in years (Mean $\pm S D$ ) & $19.1 \pm 2.6$ & \\
\hline \multicolumn{3}{|c|}{ Educational status of the participant mothers } \\
\hline Illiterate/read and write & 55 & 18.3 \\
\hline Literate Certificate/primary & 45 & 15 \\
\hline Preparatory & 32 & 10.7 \\
\hline Secondary & 112 & 37.4 \\
\hline College or higher & 56 & 18.6 \\
\hline \multicolumn{3}{|l|}{ Educational status of the husbands } \\
\hline Illiterate/read and write & 33 & 11 \\
\hline Literate certificate & 8 & 2.7 \\
\hline Primary & 40 & 13.3 \\
\hline Preparatory & 28 & 9.3 \\
\hline Secondary & 139 & 46.3 \\
\hline College or higher & 52 & 17.4 \\
\hline \multicolumn{3}{|l|}{ Wife employment } \\
\hline Employed & 13 & 4.3 \\
\hline Unemployed & 287 & 95.7 \\
\hline \multicolumn{3}{|l|}{ Husband employment } \\
\hline Employed & 267 & 267 \\
\hline Unemployed & 33 & 33 \\
\hline \multicolumn{3}{|l|}{ Computer use } \\
\hline Never & 132 & 44 \\
\hline Sometimes & 112 & 37.3 \\
\hline A lot of time & 56 & 18.7 \\
\hline \multicolumn{3}{|l|}{ Per-capita income } \\
\hline Not enough+loan not repaid/big loan & 2 & 0.7 \\
\hline Not enough+small loan & 16 & 5.3 \\
\hline Just enough & 234 & 78 \\
\hline More than enough & 48 & 16 \\
\hline \multicolumn{3}{|l|}{ Family size } \\
\hline Equal to or more than 7 & 15 & 5 \\
\hline Six members & 29 & 9.7 \\
\hline Five members & 52 & 17.3 \\
\hline$<5$ & 204 & 68 \\
\hline \multicolumn{3}{|l|}{ Crowding index } \\
\hline Equal or more than 4 & 68 & 22.7 \\
\hline $2-$ & 221 & 73.7 \\
\hline$<2$ & 11 & 3.6 \\
\hline \multicolumn{3}{|l|}{ Socioeconomic level } \\
\hline High & 28 & 9.3 \\
\hline Medium & 246 & 82 \\
\hline Low & 26 & 8.7 \\
\hline
\end{tabular}

The vast majority of mothers had $1-5$ previous pregnancies. More than four-fifths had no previous abortions. Among participant mothers, four-fifth had 1-3 living children, and a minority suffered from death of previous children $(<1 \%)$. More than two-thirds of the mothers had a C-section in the last delivery, while a quarter of them had previous normal vaginal deliveries, as shown in Table 2.

Table 2: Reproductive history of the study participants

\begin{tabular}{|c|c|c|}
\hline Reproductive history & Number (300) & Percentage \\
\hline \multicolumn{3}{|c|}{ Number of previous pregnancies } \\
\hline Primigravida & 14 & 4.7 \\
\hline $1-5$ previous pregnancies & 283 & 94.3 \\
\hline Multiparous (>5) & 3 & 1 \\
\hline \multicolumn{3}{|l|}{ Number of previous abortions } \\
\hline None & 251 & 83.7 \\
\hline $1-2$ & 46 & 15.3 \\
\hline 3 and more & 3 & 1 \\
\hline \multicolumn{3}{|l|}{ Number of living girls } \\
\hline None & 106 & 35.3 \\
\hline $1-2$ & 170 & 56.7 \\
\hline 3 and more & 23 & 8 \\
\hline \multicolumn{3}{|l|}{ Number of living boys } \\
\hline None & 74 & 24.7 \\
\hline $1-2$ & 217 & 72.3 \\
\hline 3 and more & 9 & 3 \\
\hline \multicolumn{3}{|l|}{ Number of living children } \\
\hline None & 14 & 4.7 \\
\hline $1-3$ & 244 & 81.3 \\
\hline 4 and more & 42 & 14 \\
\hline \multicolumn{3}{|c|}{ Number of previous children deaths } \\
\hline None & 297 & 99.1 \\
\hline At birth & 1 & 0.3 \\
\hline $1^{\text {st }}$ month & 1 & 0.3 \\
\hline $1^{\text {st }}$ year & 1 & 0.3 \\
\hline \multicolumn{3}{|l|}{ Type of last delivery } \\
\hline None & 14 & 4.7 \\
\hline Normal vaginal & 78 & 26 \\
\hline C-section & 208 & 69.3 \\
\hline
\end{tabular}

Two-thirds of the interviewed mothers were suffering from variable degrees of depression. Table 3 and Figure 1 show the categories and the scores of HRSD of the interviewed mother.

Table 3: Hamilton Rating Scale for depression of the interviewed mothers

\begin{tabular}{lll}
\hline Hamilton categories & Number (300) & Percentage \\
\hline Normal (0-7) & 94 & 31.3 \\
Mild depression (8-13) & 121 & 40.3 \\
Moderate depression (14-18) & 67 & 22.4 \\
Severe depression (19-22) & 12 & 4 \\
Very severe depression ( 23$)$ & 6 & 2 \\
Hamilton score median (IQR) & $10(7-14)$ & \\
\hline
\end{tabular}

Table 4 displays the socioeconomic characters versus the outcome of pregnancy. As regards unfavorable outcome, it was found that the higher percentages of unfavorable outcome were found among mothers who had primary/preparatory/secondary education, higher education of husbands, unemployed mothers, employed husbands, divorced/widow mothers (significant association), living in husband's family's home, mothers who use a computer sometimes, those who did not have enough income, family size of 6 members, higher crowding index (equal or more than 4), and medium SE score.

Table 5 displays the reproductive health versus the outcome of pregnancy. As regards the unfavorable outcome of pregnancy, it was found that the higher percentages of an unfavorable outcome of pregnancy were found in mothers with 1-5 pregnancies, 3 and more previous abortions, three or more living girls, no previous children's deaths, previous C- section, and no desire to current pregnancy. These differences were not statistically significant.

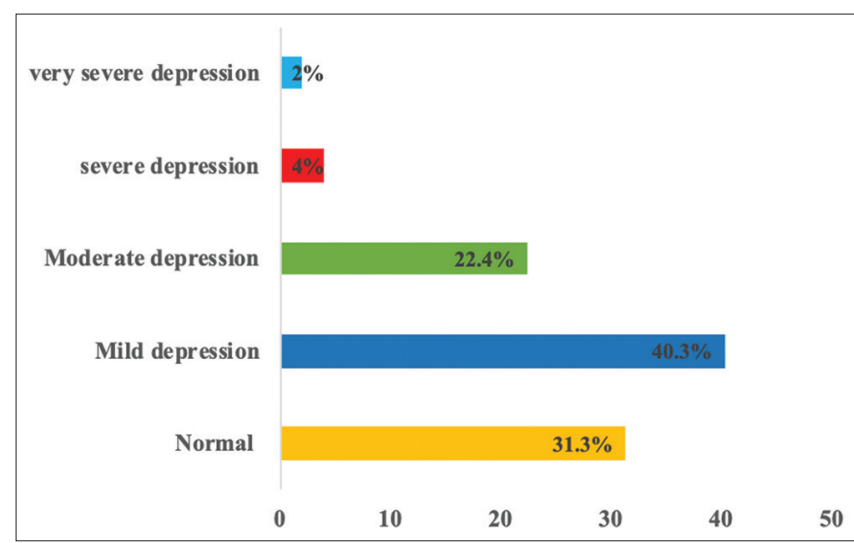

Figure 1: Hamilton Rating Scale for depression of the interviewed mothers

Table 6 displays antepartum depression versus different birth outcomes; it was found that the incidence of LBW babies was higher in mothers with severe depression followed by that in mothers with moderate depression. This difference was highly significant $(p<0.001)$. It was found that the higher percentages of NICU admission were found in mothers with severe depression followed by that in mothers with moderate depression, then by that in mothers with mild depression. These differences were highly statistically 
Table 4: Association between socioeconomic characters and outcome of pregnancy

\begin{tabular}{|c|c|c|c|}
\hline Variables & Favorable outcome & Unfavorable outcome & $p$ value \\
\hline Mother age (mean $\pm \mathrm{SD})$ & $25.7 \pm 4.6$ & $26.7 \pm 5.5$ & 0.134 \\
\hline Mother age at marriage & $19.2 \pm 2.5$ & $18.9 \pm 2.9$ & 0.469 \\
\hline \multicolumn{4}{|l|}{ Educational status of wife: No (\%) } \\
\hline Illiterate/read and write & $45(81.8)$ & $10(18.2)$ & \multirow[t]{3}{*}{0.379} \\
\hline Primary/preparatory/secondary & $144(76.2)$ & $45(23.8)$ & \\
\hline College or higher & $47(83.9)$ & $9(16.1)$ & \\
\hline \multicolumn{4}{|c|}{ Educational status of husband: No (\%) } \\
\hline Illiterate/read and write & $32(78.0)$ & $9(22.0)$ & \multirow{3}{*}{0.93} \\
\hline Primary/preparatory/secondary & $164(79.2)$ & $43(20.8)$ & \\
\hline College or higher & $40(76.9)$ & $12(23.1)$ & \\
\hline \multicolumn{4}{|l|}{ Wife employment: No (\%) } \\
\hline Unemployed & $224(78.0)$ & $63(22.0)$ & \multirow[t]{2}{*}{0.220} \\
\hline Employed & $12(92.3)$ & $1(7.7)$ & \\
\hline \multicolumn{4}{|l|}{ Husband employment: No (\%) } \\
\hline Unemployed & $27(81.8)$ & $6(18.2)$ & \multirow[t]{2}{*}{0.639} \\
\hline Employed & $209(78.3)$ & $58(21.7)$ & \\
\hline \multicolumn{4}{|l|}{ Social status: No (\%) } \\
\hline Married & $236(79.2)$ & $62(20.8)$ & \multirow[t]{2}{*}{$0.006^{*}$} \\
\hline Divorced/widow & $0(0.0)$ & $2(100.0)$ & \\
\hline \multicolumn{4}{|l|}{ Living place: No (\%) } \\
\hline Own home/parent home & $159(79.5)$ & $41(20.5)$ & \multirow[t]{2}{*}{0.618} \\
\hline Husband family home & $77(77.0)$ & $23(23.0)$ & \\
\hline \multicolumn{4}{|l|}{ Computer use: No (\%) } \\
\hline Never & $104(78.8)$ & $28(21.2)$ & \multirow[t]{3}{*}{0.487} \\
\hline Sometimes & $85(75.9)$ & $27(24.1)$ & \\
\hline Frequently & 47 (83.9) & $9(16.1)$ & \\
\hline \multicolumn{4}{|l|}{ Per-capita income: No (\%) } \\
\hline Not enough & $12(66.7)$ & $6(33.3)$ & \multirow[t]{3}{*}{0.237} \\
\hline Just enough & $183(78.2)$ & $51(21.8)$ & \\
\hline More than enough & $41(85.4)$ & $7(14.6)$ & \\
\hline \multicolumn{4}{|l|}{ Family size: № (\%) } \\
\hline Equal to or more than 7 & $10(66.7)$ & $5(33.3)$ & \multirow[t]{4}{*}{0.132} \\
\hline Six members & $19(65.5)$ & $10(34.5)$ & \\
\hline Five members & $40(76.9)$ & $12(23.1)$ & \\
\hline$<5$ & $167(81.9)$ & $37(18.1)$ & \\
\hline \multicolumn{4}{|l|}{ Crowding index: No (\%) } \\
\hline $1-3$ & $186(80.2)$ & $46(19.8)$ & \multirow[t]{2}{*}{0.240} \\
\hline Equal or more than 4 & $50(73.5)$ & $18(26.5)$ & \\
\hline \multicolumn{4}{|l|}{ SE levels } \\
\hline High & $25(89.3)$ & $3(10.7)$ & \multirow[t]{3}{*}{0.325} \\
\hline Medium & $190(77.2)$ & $56(22.8)$ & \\
\hline Low & $21(80.8)$ & $5(19.2)$ & \\
\hline
\end{tabular}

Table 5: Association between reproductive health and outcome of pregnancy

\begin{tabular}{|c|c|c|c|}
\hline Variables & $\begin{array}{l}\text { Favorable } \\
\text { outcome no (\%) }\end{array}$ & $\begin{array}{l}\text { Unfavorable } \\
\text { outcome no (\%) }\end{array}$ & $p$ value \\
\hline \multicolumn{4}{|c|}{ Number of previous pregnancies } \\
\hline Primigravida & $13(92.9)$ & $1(7.1)$ & \multirow[t]{3}{*}{0.267} \\
\hline $1-5$ pregnancies & $220(77.7)$ & $63(22.3)$ & \\
\hline More than 5 pregnancies & $3(100.0)$ & $0(0.0)$ & \\
\hline \multicolumn{4}{|l|}{ Number of previous abortions } \\
\hline None & $200(79.7)$ & $51(20.3)$ & \multirow[t]{3}{*}{0.135} \\
\hline $1-2$ & $35(76.1)$ & $11(23.9)$ & \\
\hline 3 and more & $1(33.3)$ & $2(66.7)$ & \\
\hline \multicolumn{4}{|l|}{ Number of living girls } \\
\hline None & $86(81.1)$ & $20(18.9)$ & \multirow[t]{3}{*}{0.294} \\
\hline $1-2$ & $134(78.8)$ & $36(21.2)$ & \\
\hline 3 or more & $16(66.7)$ & $8(33.3)$ & \\
\hline \multicolumn{4}{|l|}{ Number of living boys } \\
\hline None & $63(85.1)$ & $11(14.9)$ & \multirow[t]{3}{*}{0.192} \\
\hline $1-2$ & $165(76.0)$ & $52(24.0)$ & \\
\hline 3 or more & $8(88.9)$ & $1(11.1)$ & \\
\hline \multicolumn{4}{|l|}{ Number of living children } \\
\hline None & $13(92.9)$ & $1(7.1)$ & \multirow[t]{3}{*}{0.129} \\
\hline $1-3$ & $194(79.5)$ & $50(20.5)$ & \\
\hline 4 or more & $29(69.0)$ & $13(31.0)$ & \\
\hline \multicolumn{4}{|c|}{ Number of previous child deaths } \\
\hline Zero & $233(78.5)$ & $64(21.5)$ & \multirow[t]{4}{*}{0.844} \\
\hline At birth & $1(100.0)$ & $0(0.0)$ & \\
\hline $1^{\text {st }}$ month & $1(100.0)$ & $0(0.0)$ & \\
\hline $1^{\text {st }}$ year & $1(100.0)$ & $0(0.0)$ & \\
\hline \multicolumn{4}{|l|}{ Type of last delivery (286) } \\
\hline Normal vaginal & $55(70.5)$ & $23(29.5)$ & \multirow[t]{2}{*}{0.834} \\
\hline C-section & $144(96.2)$ & $64(30.8)$ & \\
\hline \multicolumn{4}{|l|}{ Desire to current pregnancy } \\
\hline Yes & $218(79.9)$ & $55(20.1)$ & \multirow[t]{2}{*}{0.111} \\
\hline No & $18(66.7)$ & $9(33.3)$ & \\
\hline
\end{tabular}

significant $(p<0.001)$. It was found that higher percentages of death in the $1^{\text {st }}$ month of life were found in mothers with severe depression followed by those
Table 6: Association between antepartum depression and different birth outcomes

\begin{tabular}{|c|c|c|c|c|c|}
\hline & \multicolumn{4}{|c|}{ Depression levels } & \multirow[t]{2}{*}{$p$ value } \\
\hline & Normal & Mild & Moderate & Severe & \\
\hline \multicolumn{6}{|l|}{ Gestational age } \\
\hline Full term No (\%) & $94(100.0)$ & $120(99.2)$ & $64(95.5)$ & $17(94.4)$ & \multirow[t]{2}{*}{0.072} \\
\hline Preterm No (\%) & $0(0.0)$ & $1(0.8)$ & $3(4.5)$ & $1(5.6)$ & \\
\hline \multicolumn{6}{|l|}{ Birth weight } \\
\hline Normal/HBW No (\%) & 93 (98.9) & $121(100.0)$ & 66 (98.5) & $13(72.2)$ & \multirow[t]{2}{*}{$<0.001$} \\
\hline LBW No (\%) & $1(1.1)$ & $0(0.0)$ & $1(1.5)$ & $5(27.8)$ & \\
\hline \multicolumn{6}{|l|}{ NICU admission } \\
\hline No & $84(89.4)$ & $98(81.0)$ & $47(70.1)$ & $9(50.0)$ & \multirow[t]{2}{*}{$<0.001^{*}$} \\
\hline Yes & $10(10.6)$ & $23(19.0)$ & $20(29.9)$ & $9(50.0)$ & \\
\hline \multicolumn{6}{|l|}{ Death in $1^{\text {st }}$ month of life } \\
\hline No & $94(100.0)$ & $121(100.0)$ & 64 (95.5) & $12(66.7)$ & \multirow[t]{2}{*}{$<0.001$} \\
\hline Yes & $0(0.0)$ & $0(0.0)$ & $3(4.5)$ & $6(33.3)$ & \\
\hline \multicolumn{6}{|l|}{ Birth outcome } \\
\hline Favorable & $83(88.3)$ & $98(81)$ & $47(70.1)$ & $8(44.4)$ & \multirow[t]{2}{*}{$<0.001^{*}$} \\
\hline Unfavorable & $11(11.7)$ & $23(19)$ & $20(29.9)$ & $10(55.6)$ & \\
\hline
\end{tabular}

with moderate depression. On the other hand, death in the $1^{\text {st }}$ month of life was not recorded in mothers who did not suffer from depression. These differences were highly statistically significant $(p<0.001)$.

Table 6 shows that NICU admission was reported in 62 infants $(20.7 \%)$, death in $1^{\text {st }}$ month of life were 9 infants $(3 \%)$, preterm 5 infants $(1.7 \%)$, and LBW 7 infants (2.3\%). From Table 6 and Figure 2, one can conclude that increasing level of depression is significantly associated with the incidence of adverse birth outcome.

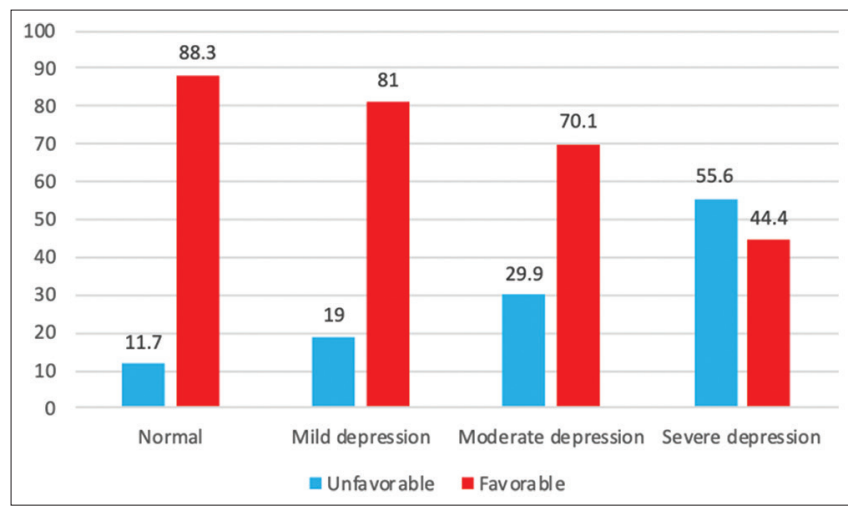

Figure 2: Level of depression and birth outcome

Table 7 shows the significant predictors of unfavorable birth outcome using logistic regression.

Table 7: Significant predictors of unfavorable birth outcome

\begin{tabular}{lllll}
\hline Predictors & Exp (B) & $95 \% \mathrm{Cl}$ & & p value \\
\hline Constant & 0.13 & & & $<0.001$ \\
Depression level & & & & \\
$\quad$ Mild & 1.77 & 0.81 & 3.8 & 0.14 \\
$\quad$ Moderate & 3.21 & 1.4 & 7.2 & 0.005 \\
$\quad$ Severe & 9.43 & 3.07 & 28.9 & $<0.001$ \\
Normal (reference) & & & & \\
\hline
\end{tabular}

All significant variables that resulted from bivariate analysis were entered in the model. The only significant predictor was depression level. Females with a severe level of depression had a 9.43 higher risk of incidence of unfavorable birth outcome than females without depression. Furthermore, females with a moderate level of depression had a 1.4 higher risk of incidence of unfavorable birth outcome than females without depression. 


\section{Discussion}

Although antepartum depression, anxiety, and stress have serious long-term implications on both mother and baby [22], still mental health is a neglected issue in healthcare settings and remains of low priority in Egypt [23].

This study revealed that two-thirds of mothers suffered from antepartum depression. This with a crossfinding was a consistent sectional study conducted in Egypt in 2013 that included 376 pregnant women attending the ANC outpatient clinic at the largest university hospital (Kasr Alainy). That study reported that women who expressed simultaneous anxiety and depressive manifestations accounted for $63 \%$ [24].

A higher percentage of antepartum depression was reported by a study performed in Karachi, where the prevalence of antepartum depression was $81 \%$ [20].

On the other hand, lower prevalence of antepartum depression was reported in Australia (7\%) [25] and in Hong Kong (4.4\%) [26]. The differences in the prevalence of antepartum depression between the current study and the studies from other countries might be attributed to sociodemographic and economic differences. In addition to that, methodological differences between studies like types of screening tool used, gestational time point when screened for symptoms, sample size, and sample characteristics might explain those differences. Furthermore, there is a possibility of underestimation of antepartum depression in the other studies due to less participation of depressed mothers in research. This might be due to their fear, denial, and avoidance of stigma related to mental illness. It might be also due to a lack of seeking mental health services, probably because symptoms of depression could be mistaken for physiological and hormonal changes that occur during pregnancy.

The current study reported that unfavorable outcome of pregnancy, in the form of preterm birth (PTB), LBW, NICU admission, and death in the $1^{\text {st }}$ month of life was reported with depressed pregnant mothers. This finding was consistent with a systematic review and meta-analysis conducted to investigate the burden of antepartum depression and its consequences on birth outcomes in low- and middle-income countries. It explored that the risk of adverse birth outcomes (LBW or PTB) was 1.59 times higher among pregnant mothers who had depression compared to those who did not [8].

Antepartum depression is often considered to be a predictor of increased incidence of PTB, miscarriages, retarded fetal growth, which can manifest as LBW [27].

A prospective cohort study included 799 pregnant women from health clinics of two states in east and west coasts of Malaysia. They studied the impact of maternal antepartum depressive and anxiety symptoms on birth outcomes. That study reported that pregnant women with depressive symptoms had an increased risk of giving birth to babies with LBW (relative risk 3.58; 95\% confidence interval [Cl] 2.16-5.94) compared to women without depressive symptoms [28].

In Egypt, a study performed on 54 pregnant mothers explored that women with depressive and anxiety symptoms in the third trimester exhibited an increased likelihood of having oligohydramnios, diminished placental perfusion. In addition, $45.5 \%$ of them showed intrauterine growth restriction [29].

An increased PTB risk among mothers with depression was consistent with a meta-analysis published by Grigoriadis et al. [30]. Similarly, risk of PTB and risk of LBW were reported in a meta-analysis conducted by Grote, which is also in line with the current finding [31].

A similar finding was reported by a prospective cohort study in China, where 1377 pregnant women were recruited. It concluded that offspring born to women with antepartum depression was more likely to be of LBW than offspring born to women without antenatal depression (odds ratio 2.39, 95\% Cl: 1.17-4.89) [32].

A systematic review and meta-analysis were performed to study neonatal outcomes in women with untreated antepartum depression compared with women without depression. Untreated depression was found to be a significant risk of 2 perinatal outcomes; PTB and LBW [33].

\section{Limitations of the study}

The external validity of the results of the current study is limited due to including only rural women who received $\mathrm{ANC}$ from $\mathrm{PHC}$ units.

\section{Conclusion}

This prospective cohort study revealed that two-thirds of participating rural women (who were apparently healthy and free from medical problems after examination by obstetrician) suffered from variable degrees of antepartum depression as detected by HRSD. The level of depression was found to be the only significant predictor of unfavorable birth outcome in the form of preterm, LBW, NICU admission, and death in $1^{\text {st }}$ month of life.

\section{Recommendations}

The policymakers should consider delivering mental health services at health facilities during ANC. 
This should be associated with increase health literacy of females about the importance of mental health. Future studies are recommended to assess the impact of improving awareness of mothers about antepartum depression on pregnancy outcome in the next birth cycle.

\section{References}

1. Lund C, Schneider M, Garman EC, Davies T, Munodawafa M, Honikman S, et al. Task-sharing of psychological treatment for antenatal depression in Khayelitsha, South Africa: Effects on antenatal and postnatal outcomes in an individual randomised controlled trial. Behav Res Ther 2020;130:103466. https://doi. org/10.1016/j.brat.2019.103466

PMid:31733813

2. Bindt C, Appiah-Poku J, Te Bonle M, Schoppen S, Feldt T, Barkmann $\mathrm{C}$, et al. Antepartum depression and anxiety associated with disability in African women: Cross-sectional results from the CDS study in Ghana and Côte d'Ivoire. PLoS One. 2012;7(10):e48396. https://doi.org/10.1371/journal. pone.0048396

PMid:23110236

3. World Health Organization. Other Common Mental Disorders: Global Health Estimates. Geneva: World Health Organization; 2017. p. 1-24.

4. Mossie TB, Sibhatu AK, Dargie A, Ayele AD. Prevalence of antenatal depressive symptoms and associated factors among pregnant women in Maichew, North Ethiopia: An institution based study. Ethiop J Health Sci 2017;27(1):59-66. https://doi. org/10.4314/ejhs.v27i1.8

PMid:28458491

5. Union A. Status Report on Maternal Newborn Child and Adolescent Health: Focusing on Unfinished Business in Africa. Second Session of the Specialized Technical Committee on Health, Population and Drug Control (Stc-Hpdc-2) Addis Ababa, Ethiopia; 2017

6. Ayele TA, Azale T, Alemu K, Abdissa Z, Mulat H, Fekadu A. Prevalence and associated factors of antenatal depression among women attending antenatal care service at Gondar University Hospital, Northwest Ethiopia. PLoS One. 2016;11(5):e0155125. https://doi.org/10.1371/journal pone. 0155125

PMid:27153193

7. Sharma P, Singh N, Tempe A, Malhotra M. Psychiatric disorders during pregnancy and postpartum. J Pregnancy Child Health. 2017;4(317):2. https://doi.org/10.4172/2376-127x.1000317

8. Fekadu Dadi A, Miller ER, Mwanri L. Antenatal depression and its association with adverse birth outcomes in low and middleincome countries: A systematic review and meta-analysis. PLoS One. 2020;15(1):e0227323. https://doi.org/10.1371/journal. pone. 0227323

PMid:31923245

9. Anwar N, Thamarangsi T. Care for mental disorders and promotion of mental well-being in South-East Asia. WHO South East Asia J Public Health. 2017;6(1):1-4. https://doi. org/10.4103/2224-3151.206157 PMid:28597851

10. Joshi D, Shrestha S, Shrestha N. Understanding the antepartum depressive symptoms and its risk factors among the pregnant women visiting public health facilities of Nepal. PLoS
One. 2019;14(4):e0214992. https://doi.org/10.1371/journal. pone.0214992

PMid:30947251

11. CAPMAS. Central Agency for Public Mobilization and Statistics (CAPMAS), Egypt in Figures; 2014.

12. Available from: https://www.openepi.com/SampleSize/ SSCohort.htm. [Last accessed on 10 Apr 2021].

13. Fahmy S. Determining simple parameters for social classifications for health research. Bull High Inst Public Health. 1983;13:95-108.

14. Fahmy SI, Nofal LM, Shehata SF, El Kady HM, Ibrahim HK Updating indicators for scaling the socioeconomic level of families for health research. J Egypt Public Health Assoc. 2015;90(1):17. https://doi.org/10.1097/01.epx.0000461924.05829.93 PMid:25853538

15. Hamilton M. A rating scale for depression. J Neurol Neurosurg Psychiatry. 1960;23(1):56-62.

PMid:14399272

16. Bachner YG. Psychometric properties of responses to an Arabic version of the Hamilton Depression Rating Scale (HAM-D6). J Am Psychiatr Nurses Assoc. 2016;22(1):27-30. https://doi. org/10.1177/1078390316629959 PMid:26929229

17. Santor DA, Gregus M, Welch A. Focus Article: Eight decades of measurement in depression. Measurement. 2006;4(3):135-55. https://doi.org/10.1207/s15366359mea0403

18. Vindbjerg E, Makransky G, Mortensen EL, Carlsson J. Crosscultural psychometric properties of the hamilton depression rating scale. Can J Psychiatry. 2019;64(1):39-46. https://doi. org/10.1177/0706743718772516 PMid:29719964

19. Bagby RM, Ryder AG, Schuller DR, Marshall MB. The hamilton depression rating scale: Has the gold standard become a lead weight? Am J Psychiatry. 2004;161(12):2163-77. https://doi. org/10.1176/appi.ajp.161.12.2163 PMid:15569884

20. Jafri SA, Ali M, Ali R, Shaikh S, Abid M, Aamir IS. Prevalence of depression among pregnant women attending antenatal clinics in Pakistan. Acta Psychopathol. 2017;3(5):54. https://doi. org/10.4172/2469-6676.100126

21. World Health Organization. Training Course on Child Growth Assessment. WHO Child Growth Standards. Geneva: World Health Organization; 2008.

22. Glover V. Prenatal Stress and its Effects on the Fetus and the Child: Possible Underlying Biological Mechanisms. Perinatal Programming of Neurodevelopment. Berlin: Springer; 2015. p. 269-83. https://doi.org/10.1007/978-1-4939-1372-5_13

23. KhalifaDS, Glavin K, BjertnessE, LienL. Determinants of postnata depression in Sudanese women at 3 months postpartum: A cross-sectional study. BMJ Open. 2016;6(3):e009443. https:// doi.org/10.1136/bmjopen-2015-009443

24. Abdelhai $\mathrm{R}$, Mosleh $\mathrm{H}$. Screening for antepartum anxiety and depression and their association with domestic violence among Egyptian pregnant women. J Egypt Public Health Assoc. 2015;90(3):101-8. https://doi.org/10.1097/01 epx.0000471670.64665.8 PMid:26544838

25. Eastwood J, Ogbo FA, Hendry A, Noble J, Page A, Group EY. The impact of antenatal depression on perinatal outcomes in Australian women. PLoS One. 2017;12(1):e0169907. https:// doi.org/10.1371/journal.pone.0169907 PMid:28095461

26. Lee DT, Chan SS, Sahota DS, Yip AS, Tsui M, Chung TK. A prevalence study of antenatal depression among Chinese women. J Affect Disord. 2004;82(1):93-9. 
PMid:15465581

27. Okagbue HI, Adamu PI, Bishop SA, Oguntunde PE, Opanuga AA, Akhmetshin EM. Systematic review of prevalence of antepartum depression during the trimesters of pregnancy. Open Access Maced J Med Sci. 2019;7(9):1555-60. https://doi. org/10.3889/oamjms.2019.270

PMid:31198472

28. Nasreen HE, Pasi HB, Rifin SM, Aris MA, Ab Rahman J, Rus RM, et al. Impact of maternal antepartum depressive and anxiety symptoms on birth outcomes and mode of delivery: A prospective cohort study in east and west coasts of Malaysia. BMC Pregnancy and Childbirth. 2019;19(1):201. https://doi. org/10.1186/s12884-019-2349-9

29. Sabri $Y$, Nabel $H$. The impact of anxiety and depression during pregnancy on fetal growth and the birth outcome. Egypt J Psychiatry. 2015;36(2):95. https://doi. org/10.4103/1110-1105.158117

30. Grigoriadis S, VonderPorten EH, Mamisashvili L, Tomlinson G, Dennis CL, Koren G, et al. The impact of maternal depression during pregnancy on perinatal outcomes: A systematic review and meta-analysis. J Clin Psychiatry. 2013;74(4):e321-41. https://doi.org/10.4088/jcp.12r07968

\section{PMid:23656857}

31. Grote NK, Bridge JA, Gavin AR, Melville JL, lyengar S, Katon WJ. A meta-analysis of depression during pregnancy and the risk of preterm birth, low birth weight, and intrauterine growth restriction. Arch Gen Psychiatry. 2010;67(10):1012-24. https:// doi.org/10.1001/archgenpsychiatry.2010.111

PMid:20921117

32. Li X, Gao R, Dai X, Liu H, Zhang J, Liu X, et al. The association between symptoms of depression during pregnancy and low birth weight: A prospective study. BMC Pregnancy Childbirth. 2020;20(1):147. https://doi.org/10.1186/s12884-020-2842-1 PMid:32138708

33. Jarde A, Morais M, Kingston D, Giallo R, MacQueen GM, Giglia L, et al. Neonatal outcomes in women with untreated antenatal depression compared with women without depression:Asystematic review and meta-analysis. JAMA Psychiatry. 2016;73(8):826-37. https://doi.org/10.1001/jamapsychiatry.2016.0934

PMid:27276520 